\title{
NOVOS PARADIGMAS: PRÁTICAS COLABORATIVAS ENQUANTO FERRAMENTAS CONCRETIZADORAS DO ACESSO À JUSTIÇA
}

\author{
Fabiana Marion Spengler* \\ Maini Dornelles* \\ Rafaela Matos Peixoto Schaefer ${ }^{* * *}$
}

\begin{abstract}
RESUMO: O exaurimento da jurisdição é de conhecimento dos operadores do direito, bem como dos consumidores da justiça. Desta forma, as alternativas à jurisdição vêm sendo pensadas e precisam ser aplicadas com mais afinco. O presente trabalho traz como problema de pesquisa: advocacia colaborativa pode ser considerada um mecanismo de fomento ao acesso humanizado à justiça? O método de abordagem utilizado será dedutivo, partindo de uma premissa geral para chegar a uma específica, o procedimento utilizado será o monográfico. Concluiu-se que as práticas colaborativas, em especial o procedimento de advocacia colaborativa, podem concretizar o acesso mais humanizado à justiça.
\end{abstract}

Palavras-chave: acesso humanizado à justiça; advocacia colaborativa; jurisdição; morosidade; práticas colaborativas.

\section{NEW PARADIGMS: COLLABORATIVE PRACTICES AS IMPLEMENTING TOOLS OF ACCESS TO JUSTICE}

\begin{abstract}
The exhaustion of jurisdiction is known to the operators of law as well as consumers of justice, it is a fact that alternatives to jurisdiction have been considered and need to be applied more closely. The present work brings as a research problem: can collaborative advocacy be considered a mechanism to promote humanized access to justice? The method of
\end{abstract}

\footnotetext{
* Bolsista de Produtividade em Pesquisa do CNPq (Pq2). Pós-doutora em Direito pela Università degli Studi di Roma Tre, em Roma na Itália, com bolsa CNPq (PDE). Doutora em Direito pelo programa de Pós-Graduação stricto sensu da Universidade do Vale do Rio dos Sinos - UNISINOS - RS, mestre em Desenvolvimento Regional, com concentração na área Político Institucional da Universidade de Santa Cruz do Sul - UNISC - RS. Líder do Grupo de Pesquisa "Políticas Públicas no Tratamento dos Conflitos" certificado pelo CNPq, Coordenadora da Rede de Pesquisa em Direitos Humanos e Políticas Públicas - REDIHPP. E-mail: fabiana@unisc.br. Endereço Postal: Rua Borges de Medeiros, 76, Centro, CEP: 96810-034. Santa Cruz do Sul RS.

*** Mestranda em Direito junto ao Programa de Pós-Graduação da Universidade de Santa Cruz do Sul (UNISC), com bolsa/taxa Prosuc-Capes, modalidade II. Integrante do grupo de Pesquisa Políticas Públicas no Tratamento de Conflitos, vinculado ao CNPq, liderado pela Professora Pós-Dr ${ }^{\mathrm{a}}$ Fabiana Marion Spengler. Advogada, inscrita sob o $n^{\circ}$ de OAB/RS 112.231 E-mail: maini_md@hotmail.com. Rua Dr. Adolpho Sebastiany, 50, Centro. Sobradinho/RS, CEP: 96900-000.

**** Mestranda em Direito junto ao Programa de Pós-Graduação da Universidade de Santa Cruz do Sul (UNISC), com bolsa/taxa Prosuc-Capes. Especialista em Direito Processual Civil pela Faculdade Futura/SP. Integrante do grupo de pesquisa denominado Políticas Públicas no Tratamento de Conflitos, vinculado ao CNPq e liderado pela Professora Pós-Doutora Fabiana Marion Spengler. Mediadora voluntária de família no Projeto de Extensão "A crise da jurisdição e a cultura da paz: a mediação como meio democrático, autônomo e consensuado de tratar conflitos" da UNISC, desenvolvido junto a Defensoria Pública de Santa Cruz do Sul. Advogada. E-mail: rafaelapeixoto@mx2.unisc.br. Endereço Postal: Rua Reinoldo Schwantz, 41, Bairro Castelo Branco, CEP: 96835-284. Santa Cruz do Sul - RS.
} 
approach used will be deductive, starting from a general premise to reach a specific one, the procedure used will be the monographic. It was concluded that collaborative practices, especially the collaborative advocacy procedure can, achieve the most humanized access to justice.

Keywords: Collaborative advocacy; Collaborative practices; Humanized access to justice; Jurisdiction; Slowness.

\section{INTRODUÇÃO}

É de conhecimento geral a crise da jurisdição e a morosidade impregnada na jurisdição, por este motivo e com o intuito de estudar formas de romper o paradigma do acesso à jurisdição, enquanto acesso à justiça, que a presente pesquisa busca responder se a advocacia colaborativa pode ser considerada um mecanismo de fomento ao acesso humanizado à justiça? Para responder ao questionamento, será utilizado o método de abordagem dedutivo, partindo de uma premissa geral para que ao final possa chegar a uma específica, quanto ao procedimento será utilizado o monográfico.

Para tanto, o estudo está dividido em três tópicos. No primeiro item, será possível visualizar a crise da jurisdição e a necessidade de romper paradigmas e mudar a visão dos consumidores da justiça.

Já no segundo ponto, serão analisados os procedimentos cooperativos que visam a desjudicialização do direito, dando enfoque para as práticas de mediação e conciliação, além de verificar a diferença entre a função do advogado no método cooperativo e colaborativo.

O terceiro item tem como escopo verificar o procedimento da advocacia colaborativa, sua origem e técnicas utilizadas para instrumentar a prática que, juntamente com a mediação e a conciliação, podem ser consideradas mecanismos fomentadores da desjudicialização do direito.

Ao final, verifica-se que, apesar de não haver comprovação cientifica, as práticas colaborativas, em especial o procedimento de advocacia colaborativa, representam um instrumento concretizador do acesso mais humanizado à justiça.

\section{O EXAURIMENTO NO PODER JUDICIÁRIO E A NECESSIDADE DE NOVOS PARADIGMAS DE ACESSO À JUSTIÇA}


O comprovado ${ }^{1}$ exaurimento $^{2}$ da jurisdição no Brasil, torna o Poder Judiciário moroso e, por vezes, ineficaz no tratamento de conflitos, em função da demora no julgamento das demandas propostas. Ainda assim, muitos cidadãos optam pelo acesso à justiça por meio da jurisdição, sendo essencial que se rompa este paradigma, educando para práticas cooperativas/colaborativas.

Paradigmas se formam através do cultivo de determinada cultura. Neste item, será analisado o acesso à justiça e a necessidade que se tem na sociedade atual de romper o paradigma de acesso à jurisdição como única alternativa de acesso à justiça.

Quanto aos conceitos de acesso à justiça e acesso à jurisdição, estes não deveriam ser confundidos, o que acontece frequentemente. $\mathrm{O}$ acesso à justiça, "o mais básico dos direitos humanos", pretende garantir e não somente proclamar direitos (CAPELLETTI; GARTH, 1988, p. 12).

Já o acesso à jurisdição acontece quando o cidadão acessa o Poder Judiciário por meio de seus Tribunais, o que não deve ser confundido com "justiça”. A ideia de ser justo remete a resposta aos anseios valorativos do ser humano, sejam eles: a moralidade, a liberdade e tudo que remonta ser natural e que existe desde a antiguidade (CAVALIERI, 2002).

A jurisdição, enquanto uma das funções do Estado, consiste num sistema adversarial em que um terceiro é o substituto das partes titulares, tratando o conflito em concreto, fazendo a atuação da vontade do direito objetivo que rege a lide, caracterizando-se, ainda, pela neutralidade e imparcialidade (MORAIS; SPENGLER, 2019).

Devido ao fato de muitos cidadãos e inclusive operadores do direito confundirem o uso dos termos é que hoje o Poder Judiciário se tornou um examinador de conflitos moroso e por vezes ineficaz, face ao "destempo" 3 dos processos (SPENGLER; SPENGLER NETO, 2011).

1 A cada ano a população confia menos no Poder Judiciário, uma pesquisa realizada pela FGV (Fundação Getúlio Vargas de São Paulo), para 89\% dos entrevistados o judiciário é moroso, no quesito honestidade o índice também é alto, conforme $67 \%$ dos entrevistados o Judiciário é pouco confiável (MORAES, 2015).

2 Autores também utilizam o termo crise - porém crises são passageiras e o problema da jurisdição se perpetua com o passar dos anos. O autor Erik Navarro Wolkart utiliza o termo tragédia da justiça civil brasileira (WOLKART, 2020).

3 Tal afirmativa se deve ao fato de que o tempo, assim como perpetua situações de litígios e corrói direitos (que não são tutelados de forma adequada e "a tempo"), tem o poder de interferir na concepção processual, uma vez que se torna grande controlador da máquina judiciária. (SPENGLER; SPENGLER NETO, 2011, p. 59). 
As partes em conflito se digladiam como inimigos, como se uma soubesse exatamente o que a outra pensa, como se conhecesse todas as suas motivações, mas isso é impossível. Deve-se ensinar as partes que a consciência virtual nos faz entender o outro sempre a partir de nós mesmos! Deve-se, portanto, treinar, durante todo o processo de tentativa de solução pacífica de conflitos, que nosso Eu, representante da consciência crítica e da capacidade de escolha, deve se esvaziar o tanto quanto possível de nós mesmos, para contaminarmos menos o processo de interpretação e sermos mais justos, dosados e, em destaque, tolerantes. Sem treinamento, solução pacifica de conflitos é quase uma utopia (CURY, 2019, p.1213).

Com a promulgação da Constituição de 1988, conhecida como Constituição cidadã, o Poder Judiciário que estava afastado da sociedade, tornou próximo o cidadão e a jurisdição, o que levou ao demasiado acesso à jurisdição, ocasionando a crise e a morosidade conhecida dos jurisdicionados.

Muitas demandas sociais tornaram-se jurídicas, novos direitos são legislados, mas não são de todo modo garantidos pelo Estado, e desta forma acabam se tornando demandas jurídicas, provocando uma "explosão de litigiosidade". Assim, quando se fala em crise do Estado, este tema está intrinsecamente ligado à crise da Justiça e do próprio direito (MORAIS; SPENGLER, 2019, p. 79).

Face a demora no andamento processual, parte da população passou a desconfiar da prestação de serviços por parte do Poder Judiciário, sendo que o órgão jurisdicional, que tutela direitos e proporciona "justiça" à população, não deveria ser visto com olhos de desconfiança.

\footnotetext{
O direito ao acesso efetivo tem sido progressivamente reconhecido como sendo de importância capital entre os novos direitos individuais e sociais, uma vez que a titularidade de direitos é destituída de sentido, na ausência de mecanismos para sua efetiva reivindicação. $\mathrm{O}$ acesso à Justiça pode, portanto, ser encarado como o requisito fundamental - o mais básico dos direitos humanos - de um sistema jurídico moderno e igualitário que pretenda garantir, e não apenas proclamar os direitos de todos (CAPPELLETTI, GARTH, 1988, p. 11-12).
}

A ideia de acesso à justiça sofreu transformações importantes com o passar dos anos. O caráter individualista perdeu espaço na concepção da sociedade moderna, caracterizada por relacionamentos que assumiram um viés coletivo em virtude dos numerosos direitos e deveres sociais comunitários (SILVA, 2013).

No meio social, os conflitos são inevitáveis e salutares (especialmente se queremos chamar a sociedade na qual se insere de democrática), no entanto é importante encontrar 
meios autônomos de manejá-los, visto que uma sociedade sem conflitos é estática (MORAIS; SPENGLER, 2019).

\begin{abstract}
O ponto fundamental consiste nos mecanismos empregados para que os conflitos sejam solucionados. Se o mecanismo empregado for adequado, o resultado obtido poderá ser construtivo, edificante e propiciar, inclusive, um aprimoramento das relações pretéritas. Nesse caso, o conflito terá se tornado ocasião de aperfeiçoamento e evolução (HILL, 2020, p. 2).
\end{abstract}

A crise instaurada junto à jurisdição prejudica a concretização do acesso à justiça, ocasionando o descrédito do tutelado para com o Poder Judiciário, além de afastá-lo do senso de justiça.

A morosidade da jurisdição no Brasil é documentada no relatório elaborado anualmente pelo Conselho Nacional de Justiça (CNJ), chamado de: "Justiça em Números"4, que apontou uma taxa de congestionamento de 73\% (incluindo os processos de execução, suspensos, sobrestados e em arquivo provisório), ficando a taxa líquida de congestionamento em sede de $1^{\circ}$ grau em 59\% (CONSELHO NACIONAL DE JUSTIÇA, 2019).

Uma breve análise do relatório será posta com o intuito de comprovar cientificamente às pesquisas no que tange a ineficiência do Poder Judiciário e a necessidade na mudança de paradigma.

No ano de 2018, o tempo médio decorrido entre o protocolo de petição inicial até que fosse proferida a sentença era de 2 anos e 2 meses e entre a inicial e a baixa definitiva do processo, 3 anos. Os processos mais antigos, conhecidos como meta nacional 2, foram solucionados com mais afinco pelo Poder Judiciário (CONSELHO NACIONAL DE JUSTIÇA, 2019, p. 221).

O relatório computa os índices de conciliação pelo percentual de homologação de acordos em relação ao total de sentenças e decisões terminativas que são proferidas (CONSELHO NACIONAL DE JUSTIÇA, 2019).

\footnotetext{
4 O último relatório do CNJ publicado em 2019, apontou os dados referentes ao ano de 2018. Visando atender o princípio constitucional da publicidade, o Conselho Nacional de Justiça completa o ciclo de exposição e transparência do Poder Judiciário. Com intuito de dar ciência a todo o povo brasileiro, os números do $\mathrm{CNJ}$, apresentando dados como de, por exemplo, gastos feitos, para que e com o que, os processos julgados, para que a partir destes dados haja o aperfeiçoamento da instituição (CONSELHO NACIONAL DE JUSTIÇA, 2019).
} 
Da análise dos dados, fica claro que apesar de a conciliação ser uma política adotada pelo Conselho Nacional de Justiça há mais de 15 anos, ainda não surte os efeitos necessários para a redução da morosidade do Poder Judiciário.

É certo que o Direito é um produto cultural e por isso cada época apresenta diferentes índices de adesão à maior ou menor utilização do Poder Judiciário para resolução dos conflitos emergentes. Dada a atual preferência dos brasileiros pela via judicial é importante incentivar, disponibilizar e melhorar outros meios, auto e heterocompositivos e, simultaneamente, não se pode permitir que as demandas repetitivas continuem exigindo enfrentamento individual. $\mathrm{O}$ tratamento coletivo às demandas pseudo individuais permite soluções isonômicas e o descongestionamento da estrutura jurídica (ZANFERDINI; LIMA, 2013, p. 292).

É necessário que os operadores do direito se debrucem na busca por práticas e técnicas processuais que sirvam além da legislação, mas que cumpram a sua função social (CAPELLETTI; GARTH, 1988). Neste sentido, precisam ser pensadas e postas em prática com afinco pelos juristas e pela população, formas de acesso à justiça que rompam com o tradicional paradigma de resolução de conflitos que se dá somente através da jurisdição e por meio dela.

\footnotetext{
A mudança de lentes ao olhar para os conflitos traz uma nova concepção deles. As divergências passam a ser vistas como oportunidades alquímicas, as energias antagônicas como complementares, e o Direito como solidariedade. As velhas lentes que fragmentavam, classificavam e geravam distâncias vão para a lixeira. Começamos a entender que cada homem não é uma manada isolada, que não são fragmentos sem conexão. Cada um é interdependente e produto forçado das interações. A sociedade é unicamente produto da complexidade desses vínculos (WARAT, 2004, p. 55).
}

Neste trilhar, é preciso educar os consumidores da justiça para o consenso, tanto no âmbito social quanto acadêmico. Por mais que tais práticas já estejam institucionalizadas, o incentivo à adoção aos meios autocompositivos é dever de todos os operadores do direito, como preceitua o Código de Processo Civil. Assim sendo, para romper o paradigma adversarial exige-se além da mudança de comportamento, coragem e persistência.

Em suma, foi possível avaliar a necessidade de aprimoramento do paradigma do acesso à jurisdição, enquanto meio de acesso à justiça, para tanto no próximo item serão estudadas as práticas colaborativas que visam a promoção do acesso humanizado à justiça por meio de práticas não adversariais. 


\section{PROCEDIMENTOS COOPERATIVOS: POR UM OLHAR MAIS HUMANO NO TRATAMENTO DE CONFLITOS}

Após analisar o exaurimento da jurisdição, passaremos a analisar algumas práticas colaborativas, sendo a conciliação e a mediação objetos de estudo deste item, já a prática de advocacia colaborativa será analisada de forma minuciosa no próximo tópico deste artigo.

Antes de falar sobre os procedimentos cooperativos, insta explicar a diferença entre mecanismos cooperativos e colaborativos. Na prática cooperativa, participam os conflitantes, o terceiro mediador e os advogados - se se tratar de conciliação ou mediação judicial ${ }^{5}$. O terceiro atua com a função de auxiliar na busca por uma solução para o problema a ele confiado, porém se não for possível chegar a um acordo, o profissional que mediou o procedimento consensual não poderá representar as partes junto ao Poder Judiciário ${ }^{6}$.

Nas práticas colaborativas, especificadamente no procedimento de advocacia colaborativa, os procuradores assinam um termo de não litigância em conjunto com os clientes, caso estes não consigam chegar a um acordo extrajudicial são orientados a procurar outro profissional para lhes acompanhar na demanda judicial, pois os advogados que participaram do procedimento colaborativo não poderão atuar na via judicial (CAMERON, 2019).

As práticas colaborativas apresentam outra forma de enfrentamento de conflitos voltada para a participação pacífica dos profissionais jurídicos. Fato que representa um desafio para os profissionais preparados para o embate. Os cursos de Direito, desde seus primórdios formam profissionais litigantes. Entretanto, em 2018 foi promulgada a Resolução CNE/CES n 5/2018, que prevê que a partir de 2020, às instituições devem, no currículo do ensino jurídico, assegurar a formação humanística e o domínio das formas consensuais de conflito ${ }^{7}$.

\footnotetext{
5 Conforme estabelece o art. 334, $\S 9^{\circ}$, na via judicial as partes deverão estar acompanhadas por seus advogados ou defensores públicos. Em se tratando de sessões extrajudiciais, as partes poderão transigir sem a presença de advogados (Lei da Mediação, art. 10).

6 Art. $6^{\circ} \mathrm{O}$ mediador fica impedido, pelo prazo de um ano, contado do término da última audiência em que atuou, de assessorar, representar ou patrocinar qualquer das partes (Lei da Mediação).

7 Um exemplo de Instituição que atua firmemente na educação para práticas colaborativas é a Universidade de Santa Cruz do Sul (UNISC) que além de oferecer a disciplina em sua grade curricular, conta com um projeto de extensão voltado para a resolução consensual de conflitos juntamente com a defensoria pública do Município de Santa Cruz do Sul. Neste sentido: "A UNISC apresenta na opção disciplinas, na página do curso de Direito, a previsão da cadeira de Mediação e Arbitragem, ofertada no $4^{\circ}$ semestre, com 30 horas/aula" (STANGHERLIN; SPENGLER, 2018, p. 138). "Nessa perspectiva, a UNISC desenvolve o projeto de extensão denominado: A crise
} 
Deve-se, portanto, treinar, durante todo o processo de tentativa de solução pacífica de conflitos, que nosso $\mathrm{Eu}$, representante da consciência crítica e da capacidade de escolha, deve se esvaziar o tanto quanto possível de nós mesmos, para contaminarmos menos o processo de interpretação e sermos mais justos, dosados e, em destaque, tolerantes. Sem treinamento, solução pacifica de conflitos é quase uma utopia (CURY, 2019, p. 12-13).

Neste sentido, as práticas da mediação e da conciliação primam pela desjudicialização de ações e podem ser aplicadas a procedimentos extrajudiciais, como inventário, usucapião e divórcio.

A mediação é um mecanismo de tratar conflitos de modo consensual, no qual o mediador tem poder não autoritário, ou seja, usará sua autoridade para conduzir a sessão, mas não poderá decidir ou sugerir soluções para o conflito. Desta forma, sua função é atuar como terceiro facilitador que auxiliará as partes a chegarem ao consenso de forma voluntária, resolvendo de forma aceitável a disputa (WARAT, 2004).

O modelo de jurisdição tradicional adota a prática adversarial, no qual uma das partes perde e outra ganha, já no modelo cooperativo, proposto com base nos métodos autocompositivos, o tratamento de conflitos se dá por práticas não adversariais, fundadas no modelo ganha-ganha (SPENGLER, 2017).

Assim sendo, a mediação é considerada uma forma ecológica de resolver conflitos, sejam estes sociais ou jurídicos, pois visa à satisfação de todos os envolvidos, substituindo a aplicação de uma sanção legal imposta por um terceiro por uma resposta construída conjuntamente (MORAIS; SPENGLER, 2019).

A mediação é uma política pública caracterizada pela fraternidade, em razão disso é uma prática embasada na humanização, na inclusão e na pacificação social. Assim, almeja-se oferecer ferramentas voltadas para o diálogo e o consenso que atuem também na prevenção de novos desentendimentos. $\mathrm{O}$ intuito dos procedimentos autocompositivos, não se limita apenas a produzir efeitos no âmbito jurídico, mas no contexto social, pois é oferecido um espaço dinâmico e acolhedor no qual o foco são as pessoas e suas relações (RESTA, 2020).

da jurisdição e a cultura da paz: a mediação como meio democrático, autônomo e consensuado de tratar dos conflitos, de iniciativa da Prof. ${ }^{a}$ Fabiana Marion Spengler. Realizado e financiado pelo Departamento de Direito e apoiado pelo Programa de Pós Graduação em Direito - Mestrado e Doutorado, em parceria com os cursos de Direito e de Psicologia. Destacam-se como objetivos do projeto: a efetivação da prática da mediação extrajudicial como instrumento de acesso à justiça; o empoderamento dos mediandos e a mudança de paradigma através da percepção positiva do conflito" (SCHAEFER; SPENGLER, 2019, p. 104). 
A prática da mediação faz com que os envolvidos tragam diversos sentimentos à tona durante o procedimento, por este motivo cabe ao mediador responsável validar estes sentimentos (SPENGLER, 2017).

É nessa linha que a mediação, como ética da alteridade reivindica a recuperação do respeito e do reconhecimento da integridade e da totalidade dos espaços de privacidade do outro, repudiando o mínimo de movimento invasor e dominador (SPENGLER; SPENGLER, 2012, p. 32).

A mediação tem como objetivo central o restabelecimento de comunicação para tratar o conflito e harmonizar a relação, assim trata-se de uma política pública de inclusão social e de promoção da paz social. Algumas das principais características do procedimento ${ }^{8}$ da mediação são: privacidade, economia financeira e de tempo, oralidade, reaproximação das partes, autonomia, equilíbrio das relações (MORAIS; SPENGLER, 2019).

No ano de 2015, além do Código de Processo Civil, que prima por práticas cooperativas, foi promulgada a Lei 13.140, sendo reconhecida como marco legal da mediação (MORAIS; SPENGLER, 2019).

A Lei supracitada trata de conflitos envolvendo particulares e da autocomposição na esfera da administração pública.

Art. $1^{\circ}$, parágrafo único. Considera-se mediação a atividade técnica exercida por terceiro imparcial sem poder decisório, que, escolhido ou aceito pelas partes, as auxilia e estimula a identificar ou desenvolver soluções consensuais para a controvérsia. (BRASIL, 2015).

A mediação ganhou seu espaço no ordenamento jurídico brasileiro de forma lenta e gradual e precisa ser posta em prática com esmero pelos operadores do direito, pela sociedade, para que cumpra sua função social, concretizando o acesso à justiça de forma eficaz.

A mediação e a conciliação são políticas públicas que têm como objetivo a adequada condução do conflito a fim de viabilizar aos envolvidos que assumam o controle e juntos encontrem uma resposta consensual (SPENGLER, 2017).

A escolha de qual procedimento deve ser utilizado deriva do tipo de conflito. Spengler (2010, p. 78), define a diferença entre a conciliação e a mediação:

8 Para mais informações ver: MORAIS; SPENGLER, (2019). 
a) Quanto ao litígio: $\mathrm{Na}$ conciliação, existem litígios esporádicos, sem relacionamento prévio ou posterior entre os conflitantes (exemplo: relações de consumo envolvendo planos de saúde e seus segurados); na mediação, existem litígios cujos envolvidos possuem relações próximas e anteriores ao problema e que permanecerão - pelo menos assim se espera - íntegras após sua resolução (exemplo típico: litígios existentes entre médico e paciente ou entre o médico e hospital, entre outros);

b) Quanto ao papel do mediador/conciliador: na mediação há uma terceira pessoa que atua como mediador, ajudando os conflitantes a restabelecer a comunicação. O mediador não sugere, não propõe, não orienta. $\mathrm{O}$ conciliador, ao contrário, é o terceiro que pode sugerir, propor, orientar e direcionar o debate e seus resultados.

c) Quanto aos objetivos perseguidos: a mediação busca um tratamento adequado ao conflito que gere comunicação e satisfação dos envolvidos. O acordo pode ser uma consequência dessa dinâmica, mas um procedimento de mediação que não tenha se encerrado com um acordo não poderá ser chamado de inexitoso se possibilitou que os conflitantes voltassem a conversar. A mediação busca o consenso e a efetiva pacificação social. A conciliação tem por alvo principal alcançar o acordo, por isso é um procedimento focado na necessária composição entre as partes. O objetivo é solucionar o litígio mediante um acordo.

d) Quanto às técnicas empregadas e à dinâmica das sessões: a mediação prevê o emprego de técnicas voltadas para a escuta e o desvelamento do real interesse envolvido no conflito. É um procedimento voltado aos conflitantes que se tornam protagonistas de suas histórias e da construção de respostas aos seus problemas. A mediação prevê sessões mais longas do que a conciliação (em torno de uma hora cada uma), bem como a remarcação de tais sessões quando é necessário que o diálogo se mantenha e amadureça para que posteriormente sejam tomadas as decisões. Já a conciliação prevê o uso de técnicas de negociação mais voltadas para o acordo propriamente dito, ela estimula propostas e contrapropostas dos conflitantes e do conciliador. A conciliação acontece em sessões mais curtas e a hipótese de remarcação de novos encontros não é tão frequente (GRIFO PRÓPRIO).

Após analisar o conceito das práticas cooperativas, conceituando o procedimento de mediação e pontuando algumas diferenças com o instituto da conciliação, o próximo capítulo busca estudar o procedimento de advocacia colaborativa e a sua importância no desenvolvimento social, bem como na eficácia de um acesso à justiça mais célere e humanizado.

\section{A ADVOCACIA COLABORATIVA COMO MECANISMO DE ACESSO À JUSTIÇA}

Após perfazer um breve apanhado no que tange aos procedimentos cooperativos, neste ponto será analisado exclusivamente a advocacia colaborativa ${ }^{9}$ como um mecanismo de acesso à justiça e a sua importância para a ruptura de um paradigma.

9 A diferença entre práticas colaborativas e cooperativas fora feita no item anterior. 
O procedimento de advocacia colaborativa teve início através do advogado Stuart Webb, profissional renomado no âmbito do direito de família, que mesmo obtendo êxito nas causas em que atuava, visualizava resultados prejudiciais no que dizia respeito à vida pessoal de seus clientes, sendo que as decisões não traziam felicidade às partes. Logo, o jurista constatou que em casos de família, todos os envolvidos acabavam perdendo algo (SOUZA, SANTOS, 2018).

O processo colaborativo é centrado na descoberta de demandas e interesses específicos de acordo com a prioridade que cada parte lhes dá. As questões a serem resolvidas, são estabelecidas pelos envolvidos e não por capítulos específicos do direito de família, o que permite às partes trabalhar na solução concentrando-se no cerne das questões (CAMERON, 2019, p. 28). ${ }^{10}$

Para dar início a prática, Webb enviou uma carta para doze advogados, sendo que somente quatro responderam aceitando implementar a nova ideia. Assim, Webb seguiu advogando em conflitos da área de direito de família, mas sem utilizar a jurisdição. Passou a atuar somente visando à construção de acordos entre as partes e, caso não fosse possível, orientava o cliente a procurar novo procurador para lhe representar (GOMES, 2019).

Desta forma, Webb reformulou sua forma de atuar optando por defender os reais interesses de seus clientes, deu ênfase na realização de acordos e renunciou ao litígio (SOUZA, SANTOS, 2018).

Em 1997, surgiu o American Institute of Collaborative Professionals (Instituto
Americano de Profissionais Colaborativos), que, inicialmente, operava com
encontros mensais, informativos e um debate anual. Ocorre que, em 1999 e no ano
seguinte, as duas conferências nacionais organizadas pelo AICP mostrou a força e o
rápido crescimento das práticas colaborativas nos Estados Unidos e no Canadá, o
que despertou os idealizadores para tornar o instituto o precursor mundial do
assunto. Assim, em 2001 foi criado o International Academy of Collaborative
Professionals (Academia Internacional de Profissionais Colaborativos), nome que
perdura até os dias atuais (LARANJO, 2016, p. 8).

Peggy Thompson e Rudnei Nurse, psicólogas e inovadoras do método, trouxeram uma das maiores contribuição para a prática de advocacia colaborativa, incorporando profissionais de áreas alheias ao Direito, mas ligadas ao íntimo dos problemas a serem resolvidos nas demandas em questão (GOMES, 2019).

10 Neste ponto a autora define as práticas colaborativas utilizadas em casos de divórcio por isso diz que os envolvidos não precisam se ater ao direito de família, mas acredita-se que as práticas colaborativas podem ser utilizadas para a resolução de conflitos em outras áreas do direito. 
$\mathrm{Na}$ década de oitenta, o advogado se une a profissionais de diferentes áreas como psicólogos, médicos e consultores financeiros, visando qualificar a gestão de conflitos familiares, iniciando assim, as chamadas Collaborative Practices ${ }^{11}$ (SOUZA, SANTOS, 2018).

A advocacia colaborativa é um procedimento extrajudicial que tem como base a autonomia de vontade e a liberdade dos envolvidos para conduzir interesses patrimoniais.

\begin{abstract}
A busca dessa prática é para que o conflito existente seja resolvido em seu íntimo, fazendo com que não se rompa a relação dos envolvidos de maneira definitiva, haja vista que nasceu inicialmente no direito das famílias e esse trata diretamente com relações continuadas, em que o rompimento de um casamento com filhos, por exemplo, quando enseja no rompimento total e completo da relação dos pais gera consequências negativas para a criação dos menores (GOMES, 2019, p. 07).
\end{abstract}

No cenário brasileiro, a inclusão das práticas colaborativas ocorreu em 2011, quando as advogadas Dras. Fernanda Paiva, Flávia Soeiro e Olívia Fürst e a médica Dra. Tânia Almeida foram ao exterior buscar conhecimento acerca da realização e do procedimento das Práticas Colaborativas. Ao retornarem, com grande motivação e já capacitadas organizaram um grupo de estudos para pôr em prática seus conhecimentos (SOUZA, SANTOS, 2018).

A advocacia colaborativa, além de trazer para os envolvidos a sensação de justiça com caráter mais humanizado, é uma ferramenta que também beneficia os profissionais, visto que a cumpre sua função social, trazendo celeridade e o mesmo retorno financeiro de uma demanda judicializada que satura a todos.

No que tange ao procedimento, o início da prática se dá com a assinatura de um termo colaborativo pelas partes e pelos advogados, que se comprometem em colaborar com base nos princípios da boa fé, transparência, confidencialidade e colocar máxima vontade na resolução racional e caso não seja possível a composição, os procuradores renunciarão o direito de representação dos respectivos clientes em juízo (MAZIERO, 2018).

O mecanismo colaborativo retira do advogado o papel combativo e traz um caráter colaborativo, o que facilita a composição. Outro ponto importante é que o Estado não assume a posição de um terceiro na decisão (juiz) impondo o que é melhor para as partes, elas mesmas vão compreender o conflito e tomar suas próprias decisões com o auxílio dos profissionais capacitados.

11 Práticas Colaborativas (tradução livre). 
Para Cameron (2019), a principal característica das práticas colaborativas, independente do modelo utilizado, é que os profissionais deixam claro que só auxiliam as partes na busca por um acordo e caso não ocorra os mesmos não vão aos tribunais.

As partes envolvidas assinam um contrato de trabalho colaborativo com seus procuradores, assim devem ceder toda a documentação e as informações necessárias para que o profissional realize seu trabalho. Se o advogado souber que algo foi omitido por alguma parte, este deve se retirar do procedimento e informar a todos que aquele processo colaborativo chegou ao fim (CAMERON, 2019).

Destacam-se como características das práticas colaborativas: a racionalidade e a ausência de barganha. A racionalidade não permite que sejam postos a mesa os sentimentos das partes, visto que todos se unem para encontrar a solução mais eficaz para resolver o conflito, sem julgar quem errou. Já a ausência de barganha é uma característica voltada ao profissional colaborativo para ver quem mais ganha com o acordo. São feitas propostas de uma parte a outra até que em conjunto decidam o que é aceitável, ressalta-se que o procedimento é baseado no princípio da transparência ${ }^{12}$ (MAZIERO, 2018).

$\mathrm{Na}$ mesma esteira, a confidencialidade é basilar na realização do procedimento, tanto que caso as partes optem pelo litígio, os profissionais colaborativos não podem testemunhar, nem sequer serem intimidados a divulgar quaisquer relatórios, a não ser que todos os envolvidos estejam de acordo com a divulgação no procedimento adversarial (CAMERON, 2019).

Após algum tempo de atuação, no Brasil foi estabelecido um roteiro de funcionamento da advocacia colaborativa, que conforme Gomes (2019, p.10) é:

1) $1^{a}$ Reunião - Apenas o cliente e o advogado, que deve informar todas as possibilidades de resolução do conflito. Assim como caso o cliente opte pela advocacia colaborativa explicar o método e apresentar todos os profissionais envolvidos.

2) $2^{a}$ Reunião - O cliente, o advogado e o profissional de saúde mental já devem traçar o caminho que pretendem percorrer, identificando as maiores dificuldades jurídicas e emocionais a serem enfrentadas.

12 Aqui aponta-se a distinção entre o princípio da informação e da transparência. A informação diz respeito aos conceitos e possibilidades jurídicas, que o advogado deve transmitir ao cliente, hipossuficiente de informações. A transparência deve ser mútua entre os clientes e os advogando, tratando-se de todas e quaisquer informações relevantes ao caso em análise. Essa confiança estabelecida é que rompe com a lógica adversarial do litigio, fazendo com que a ausência das surpresas e da retenção de informações quebre com as famosas estratégias jurídicas clássicas (GOMES, 2019, p. 08). 
3) $3^{\text {a }}$ Reunião - Apenas o cliente e o profissional de saúde mental discutirão quais as demandas implícitas e o que deve ser resolvido antes da reunião face to face.

4) $4^{\text {a }}$ Reunião - Essa será a reunião face to face, ou seja, a reunião com ambos os clientes, os advogados, os profissionais de saúde

Caso seja necessário que novos encontros sejam marcados para buscar o consenso entre os envolvidos, estes são combinados de acordo com a necessidade das partes e dos profissionais envolvidos.

Quando os conflitantes entram em consenso, são livres para produzir os acordos, no qual as partes devem cumprir e obedecer a todas as regras ali estabelecidas, podendo caso queiram levar ao Poder Judiciário para homologação, entretanto não é obrigatório.

Encontrando um acordo que supra todos os requisitos de interesses de ambas as partes, estas estarão livres para redigir e elaborar um termo escrito, pelo qual estarão obrigadas a cumprir e obedecer, e que, se quiserem, poderão levar para eventual homologação do Poder Judiciário, o que, entretanto, não é absolutamente essencial em todos os casos (LARANJO, 2016, p. 15).

Como romper a velha postura litigante do advogado que se perpetua há anos nos cursos de Direito e está enraizado nas condutas profissionais do direito? Para romper paradigmas tão sólidos como estes, os profissionais colaborativos devem ser persistentes e pacientes, visto que a transformação da forma como o tratamento de conflitos é vista pela sociedade e operadores do Direito será lenta e gradual.

Acredita-se que a advocacia colaborativa, quando colocada em prática com afinco, desde o ensino nas universidades, e praticada com o devido respeito pelos profissionais, terá sucesso em curto prazo, tendo em vista que as pessoas passarão a se interessar por esta modalidade e buscarão a resolução não adversarial para tratar seus conflitos.

\section{CONCLUSÃO}

Buscou-se neste trabalho fazer uma análise sobre a importância de um novo olhar para o acesso à justiça, ou seja, a ruptura de um paradigma de desconfiança com a jurisdição e a necessidade de considerar as práticas colaborativas e cooperativas para um acesso à justiça humanizado. 
Em um primeiro momento, ao analisar o exaurimento do Poder Judiciário, restou claro a necessidade de romper paradigmas, com base nos dados expostos através de uma análise bibliográfica. No segundo momento, foram trazidos os procedimentos cooperativos, com ênfase na prática da mediação e da conciliação, enquanto que no terceiro momento foi trabalhado o procedimento de advocacia colaborativa.

Observando a indagação que norteou o presente estudo acerca da possibilidade da advocacia colaborativa ser considerada um mecanismo de fomento ao acesso humanizado à justiça, verificou-se que a resposta se dá no sentido positivo, tendo em vista que foi possível avistar as características das práticas colaborativas e das cooperativas, bem como os benefícios alcançados por meio do método colaborativo de enfrentamento de conflitos adotado pelas partes e pelos profissionais.

As práticas cooperativas, apesar de já institucionalizadas, ganharam maior destaque no ordenamento jurídico em 2015, com a alteração do Código de Processo Civil e a edição do marco legal da mediação. Pensando do mesmo modo, espera-se que os procedimentos colaborativos alcancem o devido espaço no campo jurídico, aliando-se às praticas cooperativas na concretização do acesso humanizado à justiça.

Por fim, cumpre mencionar que as pesquisas científicas realizadas até o momento não dão conta de comprovar a eficácia das práticas desjudicializadoras, entretanto, acredita-se que mecanismos colaborativos e cooperativos possibilitam a mudança do tradicional paradigma de resolução de conflito fundado no modelo de justiça alcançado exclusivamente por meio do acesso à jurisdição para o paradigma consensual baseado na autonomia e no empoderamento das partes. Ademais, proporcionam a ressignificação das pessoas como protagonistas da solução, ao passo que estimulam a reeducação de comportamentos e de interesses.

\section{REFERÊNCIAS}

BRASIL. [Constituição (1988)]. Constituição da República Federativa do Brasil. Brasília, DF: Senado Federal, 1988.

. Código de Processo Civil, Lei 13.105/2015. Disponível em: http://www.planalto.

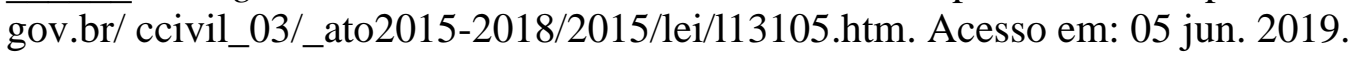

. Lei 13.140, de 26 de junho de 2015. Brasília, 2015. Disponível em: $<\mathrm{http}: / / \mathrm{www}$. planalto.gov.br/ccivil_03/_ato2015-2018/2015/Lei/L13140.htm>. Acesso em: 30 abr. 2019. 
. MINISTERIO DA EDUCAÇÃO. Resolução no 05/2018. Institui sobre as diretrizes curriculares do curso de direito. Disponível em: <http://portal.mec.gov.br/index.php? option=com_docman\&view=download\&alias=104111-rces005-18\&category_slug= dezembro-2018-pdf\&Itemid=30192>. Acesso em 23 jul. 2020.

CAMERON, Nancy J. Práticas colaborativas: aprofundando o diálogo. Tradução de Alexandre Martins. São Paulo: Instituto Brasileiro de Práticas colaborativas, 2019.

CAPPELLETTI, Mauro; GARTH, Brian. Acesso à justiça. Trad. e rev. Ellen Gracie Northfleet. Porto Alegre: Sérgio Antonio Fabris, 1988.

CAVALIERI, Sergio Filho. Direito, Justiça e Sociedade. Revista EMERJ, v. 5, n. 18, p. 5865, 2002. Disponível em: <ttp://www.emerj.tjrj.jus.br/revistaemerj_online/edicoes/revista18/ revista18_58.pdf $>$. Acesso em: 10 mar. 2020.

CONSELHO NACIONAL DE JUSTIÇA. Justiça em números. Disponível em: <http://www .cnj.jus.br/files/conteudo/arquivo/2018/08/44b7368ec6f888b383f6c3de40c32167.pdf>. Acesso em: 05 mar. 2020.

CURY, Augusto. Conheça a ti mesmo para pacificar tua mente para depois pacificar os outros, ferramentas universais de pacificação. In: CURY, Augusto. Soluções pacificas de conflitos para um Brasil Moderno. Rio de Janeiro: Editora Forense, 2019.

GOMES, Marília Studart Mendonça. Práticas colaborativas: uma alternativa de não litigância. (Re)pensando Direito, Santo Ângelo/RS, v. 09, n. 18, p. 80-92, jul./dez., 2019. Disponível em: <http://local.cnecsan.edu.br/revista/index.php/direito/index>. Acesso em: 17 maio 2020.

HILL, Flávia Pereira. Passado e futuro da mediação: perspectiva histórica e comparada. Revista de Processo, v. 45, n. 303, p. 479-502, maio, 2020. Disponível em: <https://www. thomsonreuters.com.br/content/dam/openweb/documents/pdf/ Brazil/revistasespecializadas/ repro-303-flavia-hill-passado-e-futuro-da mediacao.pdf>. Acesso em 01 set. 2020.

LARANJO, Glenda Margareth Oliveira. A Advocacia Colaborativa no Direito de Família. In: BRAGA, Sergio Pereira; MAFRA, Tereza Cristina Monteiro; CARDIN, Valéria Silva Galdino. Direito de família e sucessões I [Recurso eletrônico on-line] organização CONPEDI/UNICURITIBA- Florianópolis: CONPEDI, 2016. Disponível em: <http://conpedi. danilolr.info/publicacoes/02q8agmu/15iia5qe/HF3cjA2jo6UJ0960.pdf >. Acesso em: 10 jan. 2020.

MAZIERO, Franco Giovanni Mattedi. Inovação na solução de conflitos: a advocacia colaborativa. Percurso Acadêmico - Revista Interdisciplinar da PUC Minas no Barreiro, v. 8, n. 15, 2018. Disponível em: <http://periodicos.pucminas.br/index.php/percursoacademico/ article/view/17430>. Acesso em: 04 jun. 2020.

MORAES, Daniela Marques de. A importância do olhar do outro para a democratização do acesso à Justiça. Lumen Juris: Rio de Janeiro, 2015. 
MORAIS, Jose Luis Bolzan de; SPENGLER, Fabiana Marion. Mediação e arbitragem: alternativa à jurisdição! 4. ed. rev. e atual. Porto Alegre: Livraria do Advogado, 2019.

Resta, Eligio $O$ direito fraterno. 2. ed. Santa Cruz do Sul: Essere nel Mondo, 2020.

SCHAEFER, Rafaela Peixoto; SPENGLER, Fabiana Marion. O papel social das universidades comunitárias enquanto terceiro no tratamento dos conflitos. Revista Direito \& Paz, v. 2, n. 41, p. 91-107, 2019. Disponível em: <http://www.revista.unisal.br/lo/index.php/ direitoepaz/article/view/1140>. Acesso em 20 jul. 2020.

SILVA, Queli Cristiane Schiefelbein. O Acesso à Justiça como Direito Humano Fundamental: Retomada Histórica para Se Chegar à Concepção Atua. Revista Direito Público, v.1, n. 49, 2013. Disponível em: <https://www.portaldeperiodicos.idp.edu.br/ direitopublico/article/view/2202/1149>. Acesso em 10 mar. 2019.

SOUZA, Josan Santos; SANTOS, Claudiréia Pinheiro. Advocacia Colaborativa. Disponível em: <http://oabsergipe.org.br/wp-content/uploads/2018/10/ADVOCACIA-COLABORA TIVA.pdf.>. Acesso em: 05 jun. 2020.

SPENGLER, Fabiana Marion. Mediação de conflitos: da teoria à prática. 2. ed. rev. e ampl. Porto Alegre: Livraria do Advogado, 2017.

SPENGLER, Fabiana Marion. Mediação: um retrospecto histórico, conceitual e teórico. In: SPENGLER, Fabiana Marion; SPENGLER, Theobaldo. MEDIAÇÃO ENQUANTO POLÍTICA PÚBLICA: a teoria, a prática e o projeto de lei. Santa Cruz do Sul: EDUNISC, 2010.

SPENGLER, Fabiana Marion; SPENGLER NETO, Theobaldo. O acesso à justiça como "direito humano básico" e a crise da jurisdição no Brasil. Revista Scientia Iuris. Londrina, v. 15, n. 2, p. 53-74, dez., 2011. Disponível em: <http://www.uel.br/revistas/uel/index.php/iuris/ article/view/8501/9315>. Acesso 01 abril 2020.

STANGHERLIN, Camila Silveira; SPENGLER, Fabiana Marion. A atual formação acadêmica dos profissionais de direito e a justiça consensual: um estudo acerca das Matrizes Curriculares dos Cursos de Direito das Universidades Comunitárias do Rio Grande do SulBrasil. Revista Rios Eletrônica (FASETE), v. 1, p. 127-142, 2018. Disponível em: $<$ https://www.unirios.edu.br/revistarios/media/revistas/2018/19/a_atual_formacao_academica _dos_profissionais_de_direito_e_a_justica_consensual.pdf>. Acesso em: 15 jul. 2020.

WARAT, Luiz Alberto. Surfando na pororoca: o ofício do mediador. Florianópolis: Fundação Boiteux, 2004.

WOLKART, Erik Navarro. Análise econômica do processo Civil: como a economia, o direito e a psicologia poder vencer a tragédia da justiça. 2. Ed. São Paulo: Thomson Reuters Brasil, 2020. 
ZANFERDINI, Flávia de Almeida Motingelli; LIMA, Ticiane Garbellini Barbosa. Sociedade litigiosa: buscando soluções inconvencionais para resolver conflitos massificados. Revista Paradigma, Ribeirão Preto - SP, a. XVIII, n. 22, p. 292-308, jan./dez., 2013. Disponível em: $<$ http://revistas.unaerp.br/paradigma/article/view/295>. Acesso em 01 jun. 2020. 